Archived version from NCDOCKS Institutional Repository http://libres.uncg.edu/ir/asu/

Pine, J. C., Marx, B. D., \& Lakshmanan, A. (2002). An Examination of AccidentalRelease Scenarios from Chemical-Processing Sites: The Relation of Race to Distance. Social science quarterly, 83(1), 317-331. Published by Wiley Online Library, The version of the record is available from: http://onlinelibrary.wiley.com/journal/10.1111/\%28ISSN\%291540-6237

\title{
An Examination of Accidental-Release Scenarios from Chemical-Processing Sites: The Relation of Race to Distance
}

\author{
John C. Pine, Brian D. Marx, Aruna Lakshmanan
}

Objective. This study is intended to enhance the discussion of environmental equity by offering a methodology that is based on chemical-specific risk zones that reflect inventories of chemical facilities, risk dispersion modeling, local weather conditions, and the unique chemical processes of each site. The central question concerns whether the racial makeup of a community near a chemical-processing site is characteristic of the city, county, or community as a whole. In essence, does the racial makeup of a community vary by distance from a chemical-processing facility? Methods. A comparison of the racial makeup of the community was examined for 13 chemical-processing sites submitting off-site consequence data under the Environmental Protection Agency Risk Management Plan, by clusters of the sites, and for all sites in the community. Instead of relative ratios, we look at odds ratios. The odds ratio compares the odds of being African American to the odds of being nonAfrican American at two given distance classes. In this way we may make inferences about how much higher (or lower) are the odds of an African American (relative to a non-African American) living in a closer distance class (as opposed to a further distance class). Results. The results show that as one moves further from a facility, the characteristics of the community reflect less and less the makeup near the site. The percentage of African Americans living near a chemical-processing site tends to be much higher when compared to population characteristics further from the site. Conclusions. The study shows that distance does make a significant difference in the racial characteristics of the population from a chemical-processing site. Using data reflecting accidental-release scenarios, weather conditions, and the chemical process 
from the local community provides a more realistic basis for determining vulnerability zones.

Studies examining concerns over exposures to hazardous chemicals, as described in claims involving environmental justice, have been based on a variety of models. In most cases the studies demonstrate that racial minorities are located closer than nonminorities to environmental sources, including hazardous waste processors (Been, 1994). The critical question in most of these studies is whether the nature of the population near a site differs from that of the general population in a larger geographic area. The contention in many of these studies is that the racial and economic makeup of a community near a site is not characteristic of the community as a whole. In essence, the racial makeup of a community varies by distance from a site. This article is an effort to understand the relationship between race and distance from a site and is based on actual risk. This study tests whether race varies in a vulnerability zone by distance from a site or cluster of sites.

Some related studies have been based on a geographic area that may be insensitive to differences in the community. Cutter, Holm, and Clark (1996) and Scott et al. (1997) stress the importance of the geographic scale.

Census tracts have been used as the basis for examining demographic characteristics (Anderton, Oakes, and Fraser, 1994; Stretesky and Hogan, 1998). In a later work, Anderton (1996) stressed that the accuracy and coverage of the data available for environmental equity studies were critical and that the choice of area unit of analysis could be a determining factor in accurate analysis. Perlin et al. (1995) examined census data and found that exposure to the community is critical to any study. Using total Toxic Release Inventory (TRI) data on a county level, Perlin's study stressed the importance of the statistical tests used, the geographic units of analysis, and the nature of the comparison populations. Stretesky and Lynch (1999) also used the census tract level as a basis of analysis. Using a more discrete geographic area such as census block group could enable researchers to examine racial differences, especially where small vulnerability zones are used.

The TRI air releases data or Comprehensive Environmental Response, Compensation and Liability Information System (CERCLIS) site data is not an accurate reflection of individual exposure. CERCLIS (Stretesky and Hogan, 1998) and TRI (Perlin et al., 1995; Daniels and Friedman, 1999; United Church of Christ Commission for Racial Justice, 1987; Mohai, 1996; Oakes, Anderton, and Anderson, 1996; Yandle and Burton, 1996) sites have been the basis for some environmental justice studies. Data reported under TRI or CERCLIS are not based on dispersion models and thus do not provide a basis for determining if a specific geographic area could be exposed in a release. Strestesky and Lynch (1999) used accidentalrelease data from the Environmental Protection Agency (EPA) in predicting 
releases. The data from the chemical-release Accidental Reporting Information Program provide accidental-release information for incidents involving hazardous chemicals. Stretesky and Lynch's (1999) study was based on accidentalrelease records for reported incidents in a one-county area from 1991 through 1994. Data reflecting the risks associated with the nature of hazardous chemicals processed at a facility, the local geographic area, and weather conditions are now available through EPA's Risk Management Program (RMP) (U.S. EPA, 1997). Although the RMP data do not assess the likelihood of an accidental release, the off-site consequence data from RMP facilities provide a standardized basis for environmental justice studies.

The nature of the area affected by a hazardous site may be based on computer models. Forkenbrock and Schweitzer (1999) used computer models to establish vulnerability zones for a study of urban transportation. EPA's assessment of a proposed chemical-processing facility in Louisiana used arbitrary buffer zones as a basis of the analysis. The zones were not determined using air dispersion modeling programs (U.S. EPA, 1998). A realistic assessment should be developed of risks that are associated with actual hazardous chemicals in the community, local weather conditions, and the unique operations of a site.

\section{Methodology}

We attempt to provide a methodology for exposure from multiple chemical-processing sites clustered along the Mississippi River in Louisiana. The assessment is based on realistic exposure calculations submitted by chemical facilities to federal, state, and local government agencies under guidelines outlined by the EPA (1997).

The locations of the 13 sites examined in this study were verified by identifying the location of each facility using U.S. Geological Survey digital ortho-photo quarter quadrangles. These color photos permit a detailed examination of the community. Determining the exact location of the facility in this way avoids the use of erroneous location data as a basis of geographic analysis. The chemical-processing facilities calculated accident scenarios that conform to guidelines established by the RMP Offsite Consequence Analysis Guidance (U.S. EPA, 1999). Facilities have worked with local community officials and residents to enhance emergency planning and response efforts.

During 1998, the 13 sites examined the potential off-site impact of accidental releases under the RMP. The scenarios include both worst-case and more realistic accident scenarios based on local weather conditions, the chemical-processing characteristics of the facility, and the chemical properties of the hazardous substance. Vulnerability zones were calculated using exposure limits for young and old residents in a community rather than for healthy workers. The importance of using risk-based exposure zones in any assessment of hazards was stressed by Graham et al. (1992). The off-site buffer zones from the 13 facilities were divided into quartiles. The four risk 
zones used in this study included 1 mile, 2.5 miles, 7 miles, and 25 miles. Population counts for each of the risk zones were based on 1990 U.S. Department of Commerce, Bureau of the Census (1992) Bureau Block Group files using the geographic information system program Arclnfo.

TABLE 1

Proximity by Race Contingency Table

\begin{tabular}{lcc}
\hline & African American & Non-African American \\
\hline Proximate & W & Y \\
Not proximate & $\mathrm{X}$ & $\mathrm{Z}$ \\
\hline
\end{tabular}

\section{Previous Statistical Methods Used by the EPA}

The EPA performed comparisons examining the racial composition of populations "proximate" to a facility (U.S. EPA, 1998). A point location within a facility was used to draw three circular radii (at 1 mile, 2 miles, and 4 miles). Data for the populations within these radii were obtained from the 1990 census block-group level files. "Proximate population" was defined as an estimate of the population within a certain radius of the point location. "Nonproximate population" was the number representing the estimate of those people who did not live within the specified distance of the point location of the facility but resided within the geographic reference area (e.g., state or parish). The analysis compared the population characteristics of a single site to the local area. In addition, the buffers were inclusive, meaning that the population count in the 1-mile buffer was also included in the 2mile buffer, and so on.

For each radius at each reference area, a $2 \times 2$ table was prepared similar to the one shown in Table 1. A separate table was constructed for each of the three radii and the four geographic reference areas, for a total of 12 tables. EPA determined the proximate percentage of the total African American population in the reference area (e.g., parish). For Table 1, this proportion would be $P 1=W /(W+X)$. Similarly, the percentage of the total nonAfrican American population that is proximate in the reference area would be $P 2=Y /(Y+Z)$. These two numbers $(P 1$ and $P 2)$ were then compared. If the difference $(P 1-P 2)$ is statistically significant, then race is varying across proximate areas. This is a test for homogeneity.

In addition, the ratio $P 1$ / P2 was determined. This is called the relative ratio and was used as a measure of association between race and proximity. A ratio of $1.0(P 1=P 2)$ would indicate that there is no relationship between race and proximity.

\section{Statistical Methods Used in This Study}


In the EPA analysis, the main comparison was between the number of African Americans and non-African Americans proximate to the facility, and this was done separately for each of the three radii $(1,2$, and 4 miles). So any inferences have to be made about a certain facility at a certain radius. In our study, we seek to take further steps and model the relationship between race and distance by looking at several radii simultaneously, trying to understand how the relationship changes as we move further away or closer to a facility.

In our analysis, we examined larger tables, by using and including the radii themselves as a factor in the tables. As mentioned above, there were four risk zones $(1,2.5,7$, and 25 miles) and two races examined in this study, resulting in a $4 \times 2$ table for each location.

The distance classes were computed empirically from data provided by the participating facilities in Iberville Parish. Each site has maximum and alternative impact buffers; the distance classes ( 1 mile, 2.5 miles, and 7 miles) used in this study are approximately the 25th, 50th (median), and 75th percentiles of the set of buffers provided by the facilities, respectively. The 25-mile buffer is the maximum range of all facilities.

As we are looking at radii simultaneously, the analysis requires that we not double-count; that is, we do not want a person living 1.5 miles away from the facility included in both the 2.5-mile population and the 7-mile population. So we look at the populations within the concentric "donuts" formed by the radii and not the cumulative population at each radius (as EPA did).

Instead of relative ratios, we look at odds ratios. A relative ratio is the ratio of two probabilities (proportions), and an odds ratio is a ratio of two odds. An odds ratio, in this instance, compares the odds of being African American to the odds of being non-African American at two given distance classes. In this way we can make inferences about how much higher (or lower) are the odds of an African American (relative to a non-African American) living in a closer distance class (as opposed to a further distance class). This can be done for all radii pairs.

Such modeling strategies help explain whether or not the relationship between race and distance is getting stronger (or weaker) as distance increases and, if so, how much stronger (or weaker). Sometimes, complex phenomena may be observed. For instance, the association may be linear or follow other patterns that can be studied.

\section{Modeling Details}

Three types of analyses were conducted with the buffers from the 13 sites. First, a set of buffers of 1, 2.5, 7, and 25 miles was created to include all 13 facilities. Second, clusters of facilities were examined. In this analysis we 
grouped the sites by geographic area. Four clusters resulted from this grouping. Finally, our analysis examined distance by individual site. For each facility, we examined the odds ratios for distance classes independently. Using the set of buffers mentioned above, four distance classes were defined. Distance class 1 included the area within 1 mile of a site or the centroid

TABLE 2

Distance Class by Race Contingency Table

\begin{tabular}{lcc}
\hline & African American & Non-African American \\
\hline Distance 1-2.5 & $\mathrm{C}_{11}$ & $\mathrm{C}_{12}$ \\
Distance 2.5-7 & $\mathrm{C}_{21}$ & $\mathrm{C}_{22}$ \\
Distance 7-25 & $\mathrm{C}_{31}$ & $\mathrm{C}_{32}$ \\
Distance $>$ 25 & $\mathrm{C}_{41}$ & $\mathrm{C}_{42}$ \\
\hline
\end{tabular}

of a cluster of sites, depending on which of the three analyses is considered. Distance classes 2.5, 7, and 25 included areas between 1 and 2.5 miles, 2.5 and 7 miles, and 7 and 25 miles, respectively, from a site or centroid.

Log-linear modeling techniques were used to obtain the odds ratios mentioned in this study. Log-linear modeling is generally used to describe association and interaction patterns among a set of categorical variables. Again, we looked at associations in a $4 \times 2$ contingency table, as shown in Table 2 . Log-linear models specify how the size of a cell count is related to the levels of the categorical variables for that cell.

For the first part of the analysis, data reflecting each distance class for the 13 sites inclusively were used, and a single log-linear model was built, with Race, Distance Class, and the Race $\times$ Distance Class interaction as the factors. For the second part of the analysis, in which clusters of facilities were examined, four separate log-linear models were built, one for each cluster, using the same variables. For the third part of the analysis, 13 log-linear models were built, one for each facility.

In all cases the models used were saturated; that is, the models have as many parameters as there are observations and thus give fitted counts that are equal to the observed values. Since the Race $\times$ Distance Class interaction was found to be significant, a model simpler than the saturated model could not be fit. That is, the model was

$$
\log \left(\mu_{i j}\right)=\lambda+\lambda_{i}^{D}+\lambda_{j}^{R}+\lambda_{i j} D R,
$$

where the $\lambda_{i j}^{D R}$ are the association parameters that reflect deviations from race and distance independence. Such parameters represent interactions between race and distance, where the effect of distance on the expected counts $\left(\mu_{i j}\right)$ depends on the level for race. Such models are routinely fit 
within generalized linear models framework by assuming the cell counts in row $i$ and column $j$ follow a Poisson distribution.

In a log-linear model, the single-factor terms are the main effects $\left(\lambda_{i}^{D}\right.$ and $\left.\lambda_{j}^{R}\right)$, and the higher-order factor terms $\left(\lambda_{i j}^{D R}\right)$ represent higher-order interactions. Interpretations of the parameters refer to the highest-order terms (Agresti, 1996). Here, exponentiation of the parameter estimate gives the conditional odds ratio for the effect, controlling for the other variables in

\section{FIGURE 1}

\section{Buffers by Distance Classes}

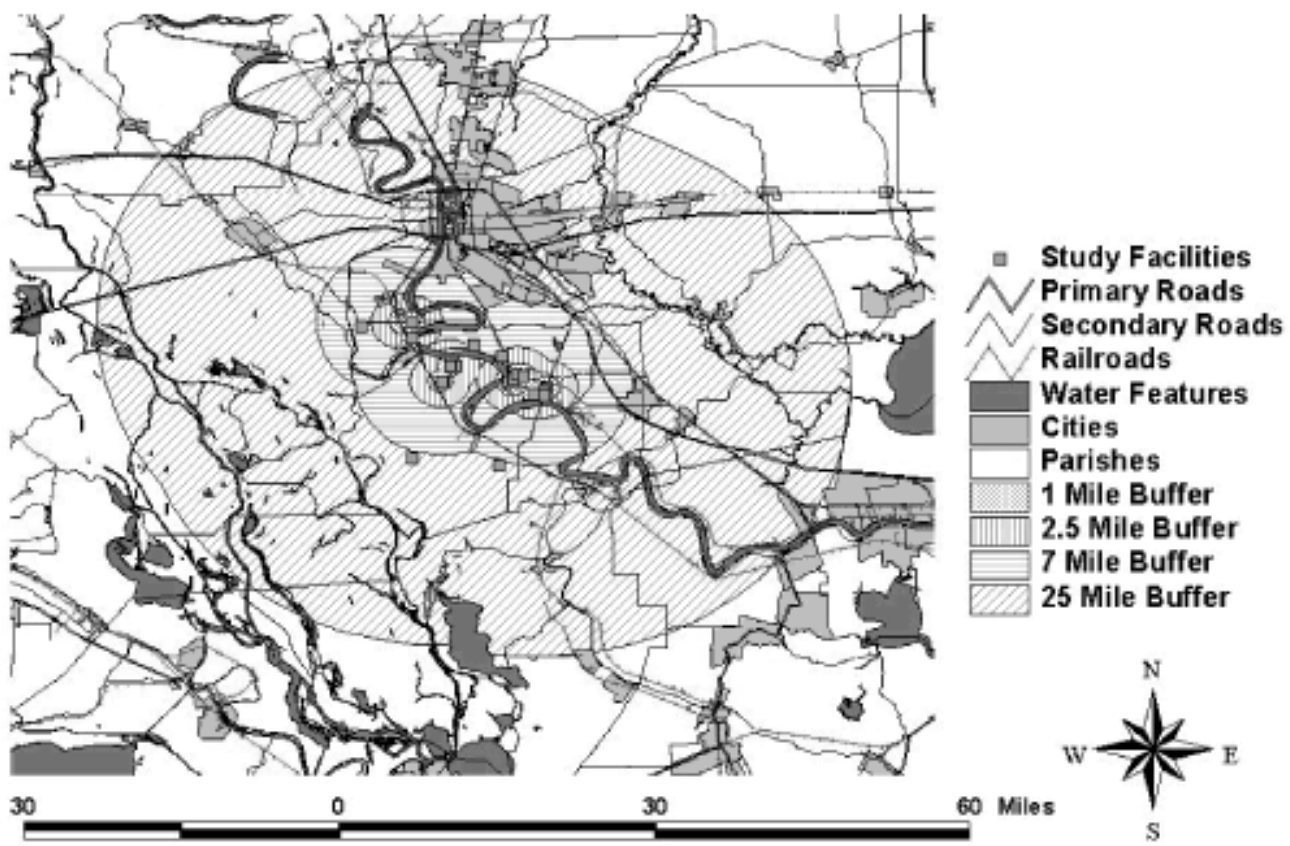

the model. For a variable such as distance class, which has more than two levels, a baseline level is chosen, and the ratio of the odds of response on the variable at any level to the odds of response at the baseline level can be computed. In this study, distance class 1 was used as a baseline. The differences between two parameters for a given variable relate to the log-odds of making one response, relative to another, on that variable. Thus, odds ratios relating to the other distance classes $2.5,7$, and 25 can be computed from the available estimates by exponentiating the differences of the parameter estimates for the two classes under consideration. For example, to find the odds ratio relating class 2.5 to class 7 , the difference between the parameter estimates relating 2.5 to 1 and those relating 7 to 1 is first computed, and this difference is then exponentiated.

\section{Interpretation of Odds Ratios}

Odds ratios are a common measure of association because they arise naturally 
in various analyses of count data such as logistic regression and loglinear modeling. Odds ratios are fundamental parameters of log-linear models and can take on all nonnegative values. An odds ratio of 1 implies that the two variables being compared are independent, and this serves as a baseline for comparison. Values of odds ratios farther from 1 in a given direction imply stronger levels of association (Agresti, 1996). For example, an odds ratio of 3 is farther from independence than an odds ratio of 2. Confidence intervals for odds ratios are useful: if the interval does not contain unity, then a significant relationship between the two variables exists.

To illustrate, when all facilities are considered, the odds ratio relating distance classes 7 and 1 and race is 2.57. This means that the odds of living between 2.5 and 7 miles from the sites as opposed to living 1 mile or less from the sites are about 2.57 times higher for a non-African American than for an African American. It also implies that the estimated odds of being non-African American over being African American are about 2.57 times higher in the area between 2.5 miles and 7 miles from the site as opposed to the area within 1 mile of the site. It can also be said that the odds of living in distance class 7 as opposed to distance class 1 are 157 percent higher for non-African Americans than for African Americans.

\section{Analysis by Buffers for All Facilities}

Figure 1 shows the geographic area included in the study with the 13 chemical-processing sites and the four distance classes 1, 2.5, 7, and 25, which are defined above. Odds ratios relating these distance classes and race were first computed, reflecting all facilities. Some of these are given below.

The odds ratio relating class 25 and class 1 is 2.4 (with 95 percent confidence interval $(2.19,2.62))$. Class 7 and class 1 are related by an odds ratio of 2.57 (with 95 percent confidence interval $(2.14,3.07)$ ), whereas the odds ratio between class 2.5 and class 1 is 1.22 (with 95 percent confidence interval $(1.10,1.35)$ ). This means that the odds of living between 7 and 25 miles from the facilities as opposed to living 1 mile or less from these sites are about 2.4 times (or 140 percent) higher for a non-African American than for an African American. Similarly, the odds of living between 2.5 and 7 miles are 2.24 times (or 124 percent) higher, and the odds of living between 1 and 2.5 miles are 1.22 (or 22 percent) higher, for a non-African American than for an African American.

The general trend that emerges is that the odds of living closer to the centroid of the 13 sites are higher for African Americans than for nonAfrican Americans. That is, the odds of being African American are significantly higher in the distance classes closer to this centroid when compared to the distance classes farther away from the centroid, no matter which two distance classes are compared, except in one case (when distance classes 7 
and 25 are considered).

\section{Analysis by Cluster of Facilities}

For the statistical analysis to investigate the relationships between the race of the residents around a cluster of chemical-processing sites, we first divided the sites into four natural clusters (see Figure 2). These clusters were

FIGURE 2

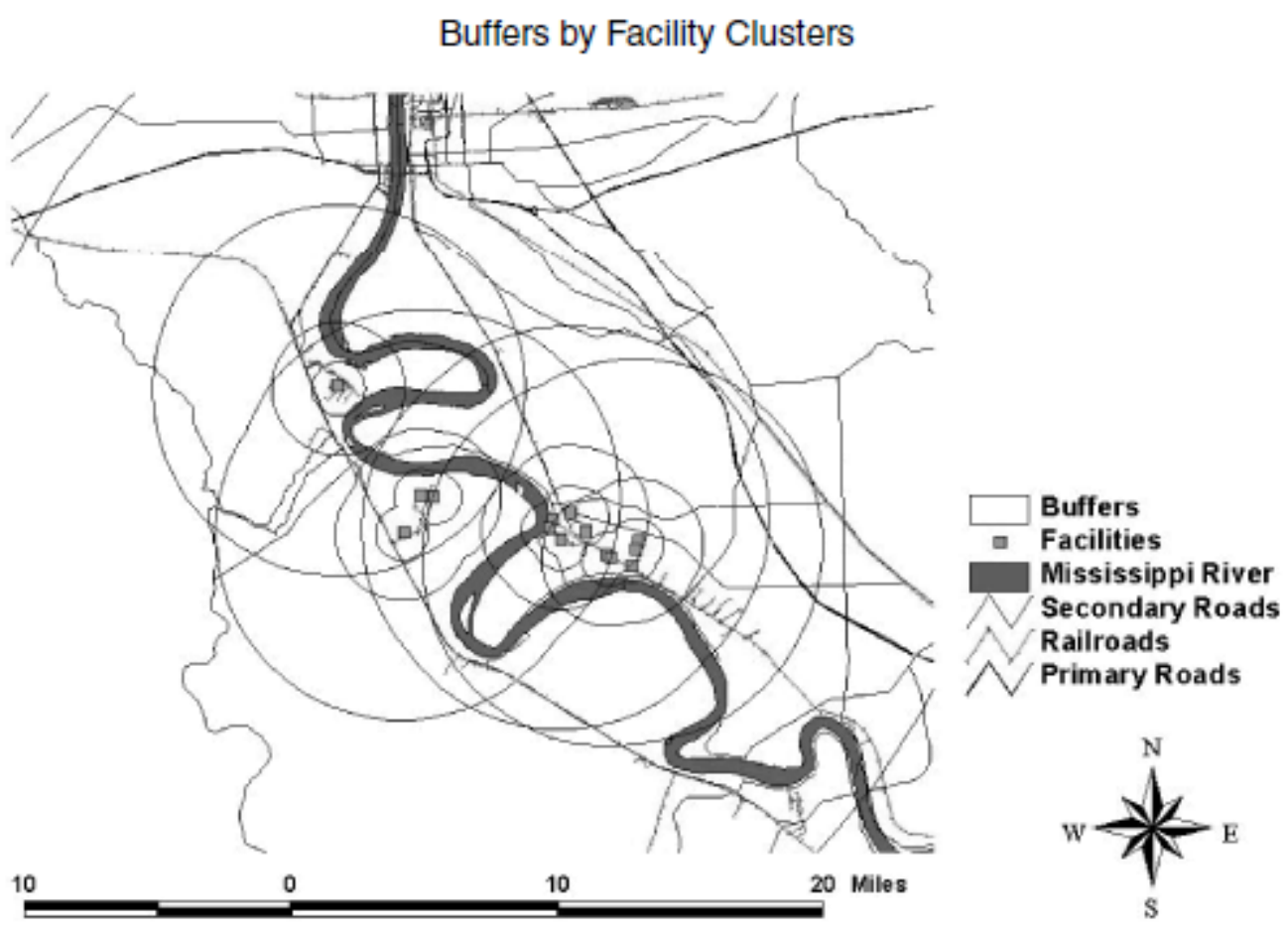

grouped with close geographic proximity of the processing sites as the determining factor. Buffers reflecting the distance classes were created for each group of facilities, as mentioned earlier. The population living in each of the classes was determined for each of the four groups of facilities. The counts for each distance class were not cumulative. The relationship between these distance classes in a group of facilities and race was then investigated using odds ratios.

Odds ratios relating distance class and race are given in Table 3. For example, the estimated odds ratio relating the distance class 25 and the distance class 1 for cluster 4 is 5.47 (with 95 percent confidence interval (4.28, 6.99)). This means that the odds of living between 7 and 25 miles from the facilities in cluster 4 as opposed to living 1 mile or less from these sites are about 5.47 times (or 447 percent) higher for a non-African American than for an African American. It also implies that the estimated odds of being non-African American over being African American are 5.47 times (or 447 percent) higher in the area between 7 and 25 miles from the cluster of sites 
as opposed to the area within 1 mile of the cluster of chemical-processing facilities.

It is clear that there is a general trend: the odds of living closer to the centroid of a cluster of facilities are higher for African Americans than they are for non-African Americans. It can also be noted that the odds ratios are higher when distance classes that are farther from each other are compared,

TABLE 3

Odds Ratios and 95 Percent Confidence Intervals by Cluster

\begin{tabular}{|c|c|c|c|c|c|c|c|c|}
\hline \multirow[b]{2}{*}{ Effect } & \multicolumn{2}{|c|}{ Cluster 1} & \multicolumn{2}{|c|}{ Cluster 2} & \multicolumn{2}{|c|}{ Cluster 3} & \multicolumn{2}{|c|}{ Cluster 4} \\
\hline & $\begin{array}{l}\text { Odds } \\
\text { Ratio }\end{array}$ & 95\% C.I. & $\begin{array}{l}\text { Odds } \\
\text { Ratio }\end{array}$ & 95\% C.I. & $\begin{array}{l}\text { Odds } \\
\text { Ratio }\end{array}$ & 95\% C.I. & $\begin{array}{l}\text { Odds } \\
\text { Ratio }\end{array}$ & $95 \%$ C. I. \\
\hline $\begin{array}{l}25-1 \\
7-1 \\
2.5-1\end{array}$ & $\begin{array}{l}1.03^{\text {n.s. }} \\
1.07^{\text {n.s. }} \\
0.85^{\text {n.s. }}\end{array}$ & $\begin{array}{l}(0.87,1.22) \\
(0.90,1.26) \\
(0.71,1.02)\end{array}$ & $\begin{array}{l}4.08^{* *} \\
2.33^{* *} \\
1.58^{*}\end{array}$ & $\begin{array}{l}(3.19,5.21) \\
(1.82,2.99) \\
(1.23,2.04)\end{array}$ & $\begin{array}{l}4.81^{* *} \\
3.14^{* *} \\
1.28^{*}\end{array}$ & $\begin{array}{l}(3.97,5.84) \\
(2.59,3.83) \\
(1.03,1.59)\end{array}$ & $\begin{array}{l}5.47^{* *} \\
3.67^{* *} \\
1.73^{* *}\end{array}$ & $\begin{array}{l}(4.28,6.99) \\
(2.87,4.70) \\
(1.32,2.25)\end{array}$ \\
\hline
\end{tabular}

in the case of clusters 2, 3, and 4, and smaller when classes closer to each other are considered.

For cluster 1, the odds ratios lack the monotonicity that is observable with the other clusters, and they are also smaller than those for the other three clusters. Cluster 1 is unique in that it contains only one facility. The other clusters have at least three facilities. In addition to the limited number of facilities in the cluster, the facility is located near more racially mixed subdivisions in the area. Subdivisions near the site tend to have families with higher incomes and include more non-African American families. The 1 and 2.5 class buffers thus tend to reflect the larger community included in buffers 7 and 25 .

\section{Analysis by Individual Facility}

A statistical analysis was also completed to investigate the race of the population around a single facility. Distance classes used in the cluster and cumulative analysis were also used with the single-site analysis. Figure 3 shows an example from one facility of the 1-mile-radii circles used to obtain a population count. Distance classes using circles of radii 1, 2.5, 7, and 25 miles were created to provide the basis for obtaining a population count by race for each radii. As with the previous analysis, the population counts were not cumulative. The relationships between these distance classes and race were then investigated using odds ratios. This analysis was completed for each of the 13 chemical-processing sites.

Odds ratios comparing distance classes 25,7 , and 2.5 to distance class 1 
are shown in Table 4. As the gap increases between the distance classes, higher odds ratios are generally found. For example, in the case of facility 7 , the odds of living between 7 and 25 miles from the facility as opposed to living within 1 mile of the site is about 6.13 times, or 513 percent higher, for a non-African American than it is for an African American. As mentioned above, the odds ratios relating classes 25,7 , and 2.5 can be computed

\section{FIGURE 3}

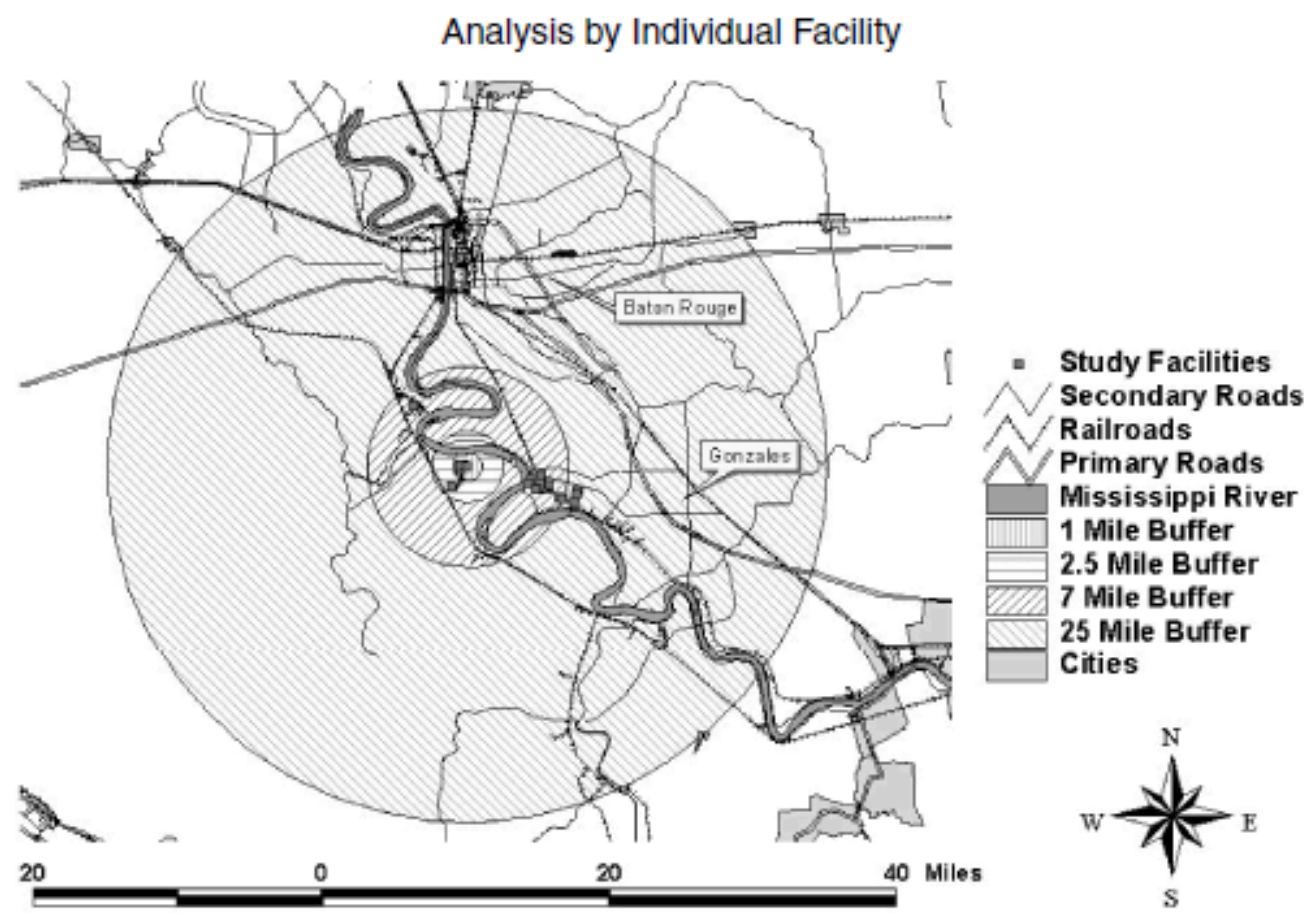

using this information. When the odds ratios were computed for each of the 13 individual facilities, the patterns that emerged largely confirmed the results of the analysis in the first two sections, indicating significant associations between race and distance class. Again, the odds of living closer to the centroid were higher for African Americans than for non-African Americans when compared to the odds of living in a distance class farther away from the centroid. For 12 out of the 13 facilities (all except for facility 1 ), the odds ratios are stronger when distance classes that are farther from each other are compared. Facility 1 does not, however, display this monotonicity. It may be recalled that facility 1 is the only member of cluster 1. As noted earlier, the characteristics of the population near this site tend to reflect the larger community and specifically the other distance classes.

\section{Conclusions}

The results of our analysis show that distance clearly makes a difference in the racial characteristics of the population. As one moves further from a 
facility, the characteristics of the community reflect less and less the makeup near the site. The percentage of African Americans living near a chemical-processing site tends to be much higher than when compared to population characteristics further from the site. Our study shows that distance does make a significant difference.

TABLE 4

Odds Ratios and 95 Percent Confidence Intervals by Facility

\begin{tabular}{|c|c|c|c|c|c|c|}
\hline \multirow[b]{2}{*}{ Effect } & \multicolumn{2}{|c|}{ Facility 1} & \multicolumn{2}{|c|}{ Facility 2} & \multicolumn{2}{|c|}{ Facility 3} \\
\hline & $\begin{array}{l}\text { Odds } \\
\text { Ratio }\end{array}$ & 95\% C.I. & $\begin{array}{l}\text { Odds } \\
\text { Ratio }\end{array}$ & 95\% C.I. & $\begin{array}{l}\text { Odds } \\
\text { Ratio }\end{array}$ & 95\% C.I. \\
\hline $\begin{array}{l}25-1 \\
7-1 \\
2.5-1\end{array}$ & \multicolumn{2}{|c|}{$\begin{array}{l}1.03^{\text {n.s. }}(0.87,1.22) \\
1.07^{\text {n.s. }}(0.90,1.26) \\
0.84^{\text {n.s. }}(0.71,1.02)\end{array}$} & $\begin{array}{l}4.21^{\star \star} \\
2.27^{\star \star} \\
1.51^{\star}\end{array}$ & $\begin{array}{l}(3.09,5.75) \\
(1.66,3.10) \\
(1.09,2.08)\end{array}$ & $\begin{array}{l}3.41 \\
2.50^{* *} \\
1.49 \text { n.s. }\end{array}$ & $\begin{array}{l}(2.17,5.38) \\
(1.59,3.94) \\
(0.94,2.37)\end{array}$ \\
\hline & \multicolumn{2}{|c|}{ Facility 4} & \multicolumn{2}{|c|}{ Facility 5} & \multicolumn{2}{|c|}{ Facility 6} \\
\hline Effect & $\begin{array}{l}\text { Odds } \\
\text { Ratio }\end{array}$ & 95\% C.I. & $\begin{array}{l}\text { Odds } \\
\text { Ratio }\end{array}$ & 95\% C.I. & $\begin{array}{l}\text { Odds } \\
\text { Ratio }\end{array}$ & 95\% C.I. \\
\hline \multirow[t]{3}{*}{$\begin{array}{l}25-1 \\
7-1 \\
2.5-1\end{array}$} & $\begin{array}{l}4.39^{* \star} \\
2.43^{* \star} \\
1.69^{*}\end{array}$ & $\begin{array}{l}(2.78,6.93) \\
(1.54,3.85) \\
(1.06,2.69)\end{array}$ & $\begin{array}{l}4.16^{\star \star} \\
2.46^{\star \star} \\
1.18^{n . s}\end{array}$ & $\begin{array}{l}(3.18,5.46) \\
(1.88,3.23) \\
(0.88,1.58)\end{array}$ & $\begin{array}{l}5.06^{* \star} \\
2.87^{\star \star} \\
1.48^{*}\end{array}$ & $\begin{array}{l}(3.77,6.81) \\
(2.13,3.87) \\
(1.08,2.03)\end{array}$ \\
\hline & \multicolumn{2}{|c|}{ Facility 7} & \multicolumn{2}{|c|}{ Facility 8} & \multicolumn{2}{|c|}{ Facility 9} \\
\hline & $\begin{array}{l}\text { Odds } \\
\text { Ratio }\end{array}$ & 95\% C.I. & $\begin{array}{l}\text { Odds } \\
\text { Ratio }\end{array}$ & 95\% C.I. & $\begin{array}{l}\text { Odds } \\
\text { Ratio }\end{array}$ & 95\% C.I. \\
\hline \multirow[t]{2}{*}{$\begin{array}{l}25-1 \\
7-1 \\
2.5-1\end{array}$} & $\begin{array}{l}6.13^{\text {** }} \\
2.61^{\text {*t }} \\
1.28^{\text {n.s. }}\end{array}$ & $\begin{array}{l}(4.45,8.46) \\
(1.89,3.61) \\
(0.91,1.81)\end{array}$ & $\begin{array}{l}5.84^{\star \star} \\
2.69^{* \star} \\
1.38^{n . s}\end{array}$ & $\begin{array}{l}(4.25,8.05) \\
(1.95,3.71) \\
(0.98,1.95)\end{array}$ & $\begin{array}{l}6.01^{\star \star} \\
2.76 \\
1.30 \text { n.s. }\end{array}$ & $\begin{array}{l}(4.28,8.43) \\
(1.96,3.88) \\
(0.91,1.87)\end{array}$ \\
\hline & \multicolumn{2}{|c|}{ Facility 10} & \multicolumn{2}{|c|}{ Facility 11} & \multicolumn{2}{|c|}{ Facility 12} \\
\hline Effect & $\begin{array}{l}\text { Odds } \\
\text { Ratio }\end{array}$ & 95\% C.I. & $\begin{array}{l}\text { Odds } \\
\text { Ratio }\end{array}$ & 95\% C.I. & $\begin{array}{l}\text { Odds } \\
\text { Ratio }\end{array}$ & 95\% C.I. \\
\hline \multirow[t]{3}{*}{$\begin{array}{l}25-1 \\
7-1 \\
2.5-1\end{array}$} & $\begin{array}{l}6.13^{* \star} \\
2.59^{* \star} \\
1.24^{\text {n.s. }}\end{array}$ & $\begin{array}{l}(4.45,8.45) \\
(1.88,3.58) \\
(0.88,1.76)\end{array}$ & $\begin{array}{l}6.06^{* \star} \\
3.03^{* *} \\
1.23^{\text {n.s. }}\end{array}$ & $\begin{array}{l}(4.37,8.41) \\
(2.18,4.22) \\
(0.86,1.75)\end{array}$ & $\begin{array}{l}5.73^{\star \star} \\
3.69^{* \star} \\
1.63^{*}\end{array}$ & $\begin{array}{l}(3.96,8.30) \\
(2.55,5.36) \\
(1.10,2.41)\end{array}$ \\
\hline & \multicolumn{2}{|c|}{ Facility 13} & & & & \\
\hline & $\begin{array}{l}\text { Odds } \\
\text { Ratio }\end{array}$ & 95\% C.I. & & & & \\
\hline $\begin{array}{l}25-1 \\
7-1 \\
2.5-1\end{array}$ & $\begin{array}{l}4.99^{* \star} \\
3.54^{* \star} \\
1.73^{\star}\end{array}$ & $\begin{array}{l}(3.60,6.91) \\
(2.55,4.92) \\
(1.22,2.44)\end{array}$ & & & & \\
\hline
\end{tabular}

*significant at the 0.0001 level.

*significant at the 0.05 level.

n.s. Not significant at the 0.05 level. 
Although the methodology used in this study is different from the approach used by EPA, our results are similar. Both show that distance makes a difference. Whereas the EPA study used only 1-, 2-, and 4-mile buffers when compared to a much larger community (7- and 25-mile buffers), the differences between the racial makeup near a site and further from it are methodology to enhance its analysis of racial differences in a community. We believe that the statistical analysis used in our study allows for comparison between races, controlling for distance class, while providing easy interpretations for associations. Future research could consider controlling for additional variables of interest, such as education level and income, in the same analysis. Alternatively, separate analyses may be done for these other variables using the same methodology.

Using buffers reflecting actual release scenarios, weather conditions, and the chemical process from the local community provides a more accurate reflection of vulnerability zones in a community. In addition, using multiple facilities allows an assessment to look beyond a single site to a communitywide focus. Clearly, the data from site 1 illustrate that multiple sites in a community should be included in a study. One should not assume that all sites would reflect the patterns shown in this study. There may be reasons why the community near one site evolved very differently from the community near other sites. A method for understanding the differences in a community needs to be used, rather than just examining the characteristics of one site.

State and local governments should examine the impact of their permitting and land use decisions on the local community. A standard process should be used by administrative agencies as they adopt or revise land use plans or air quality permits. An assessment of the nature of the local community should be a part of this administrative process. Environmental justice questions are just one perspective that could be used in such an assessment. The methodology used in this study allows for an examination of the potential risk.

We present the data in this study as observations, with no suggestion as to the reasons why the differences in distance classes exist. We presume no specific cause and effect or that one site is good where another is bad.

Although race provided the basis for this study, the same methodology may be used with other population characteristics. Income, education, percentage of the population below the poverty level, and value of homes are just a few items that could be used in an analysis of the community. A broader view of the community should be included as a part of a comprehensive assessment.

\section{REFERENCES}


Agresti, Alan. 1996. An Introduction to Categorical Data Analysis. New York: Wiley.

Anderton, Douglas. 1996. "Methodological Issues in the Spatiotemporal Analysis of Environmental Equity." Social Science Quarterly 77(3):508-15.

Anderton, Douglas, Andy B. Anderson, John M. Oakes, and Michael R. Fraser 1994. "Environmental Equity: The Demographics of Dumping." Demography 31(2):229-48.

Been, Vicki. 1994. "Locally Undesirable Land Uses in Minority Neighborhoods:

Disproportionate Siting or Market Dynamics?" Yale Law Journal 103(6):1383-1422.

Cutter, Susan, Danika Holm, and Laura Clark. 1996. "The Role of Geographic Scale in Monitoring Environmental Justice." Risk Analysis 16:517-26.

Daniels, Glynis, and Samantha Friedman. 1999. "Spatial Inequity and the Distribution of Industrial Toxic Releases: Evidence from the 1990 TRI." Social Science Quarterly 80(2):244-62.

Forkenbrock, David, and Lisa Schweitzer. 1999. "Environmental Justice in Transportation Planning." Journal of the American Planning Association 65(1):96.

Graham, John, Katherine Walker, Maurice Berry, Elizabeht Bryan, Michael Callahan, Anna Fan, Brent Finley, Jeremiah Lynch, Thomas McKone, Haluk Ozkaynak, and Ken Sexton. 1992. "Role of Exposure Databases in Risk Assessment." Archives of Environmental Health 47(6):408-13.

Mohai, Paul. 1996. "Environmental Justice or Analytical Justice? Reexamining Historical Hazardous Waste Landfill Siting Patterns in Metropolitan Texas." Social Science Quarterly 77(3):500-07.

Oakes, John, Douglas Anderton, and Andy Anderson. 1996. "A Longitudinal Analysis of Environmental Equity in Communities with Hazardous Waste Facilities." Social Science Research 25(2):125.

Perlin, Susan, Woodrow Setzer, John Creason, and Ken Sexton. 1995. "Distribution of Industrial Air Emissions by Income and Race in the United States: An Approach Using the Toxic Release Inventory." Environmental Science and Technology 29(1):69-80.

Scott, Michael, Susan Cutter, Charmel Menzel, Minhe Ji, and David Wagner. 1997. "Spatial Accuracy of the EPA's Environmental Hazards Databases and Their Use in Environmental Equity Analyses." Applied Geographic Studies 1:45-61.

Stretesky, Paul, and Michael J. Hogan. 1998. "Environmental Justice: An Analysis of Superfund Sites in Florida." Social Problems 45(2):268-88.

Stretesky, Paul, and Michael Lynch. 1999. "Environmental Justice and the Predictions 
of Distance to Accidental Chemical Releases in Hillsborough County, Florida." Social Science Quarterly 80(4):830-46.

United Church of Christ Commission for Racial Justice. 1987. Toxic Wastes and Race in the U.S.: A National Report on the Racial and Socio-Economic Characteristics of Communities with Hazardous Waste Sites. New York: United Church of Christ.

U.S. Department of Commerce, Bureau of the Census. 1992. 1990 Census of Population and Housing Summary Tape File 3A: User's Guide. Washington, D.C.: U.S. Department of Commerce.

U.S. Environmental Protection Agency. 1997. Interim Final Guidance for Incorporating Environmental Justice Concerns in EPA's NEPA Compliance Analyses. Washington, D.C.: EPA Office of Civil Rights.

1998. Title VI Administrative Complaint: Louisiana Department of Environmental Quality Permit for Proposed Shintech Facility. Washington, D.C.: EPA Office of Civil Rights.

_. 1999. Risk Management Program Guidance for Offsite Consequence Analysis. Washington, D.C.: Chemical Emergency Preparedness and Prevention (CEPP).

Yandle, Tracy, and Dudley Burton. 1996. "Reexamining Environmental Justice: A Statistical Analysis of Historical Hazardous Waste Landfill Siting Patterns in Metropolitan Texas." Social Science Quarterly 77(3):477-92. 